\title{
Publisher Correction: Melting of a skyrmion lattice to a skyrmion liquid via a hexatic phase
}

Ping Huang (iD, Thomas Schönenberger, Marco Cantoni, Lukas Heinen (D), Arnaud Magrez, Achim Rosch, Fabrizio Carbone and Henrik M. Rønnow (D)

Correction to: Nature Nanotechnology https://doi.org/10.1038/s41565-020-0716-3, published online 15 June 2020.

In the version of this Article originally published, in Fig. $3 c$, two tick marks on the $x$-axis were vertically displaced from their correct positions. The original and corrected Fig. $3 \mathrm{c}$ are shown below. The online versions of the Article have been amended.

Original

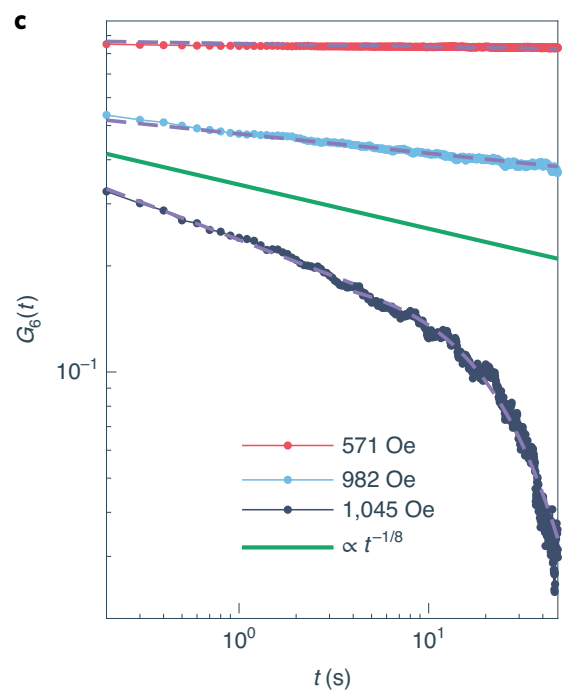

Corrected

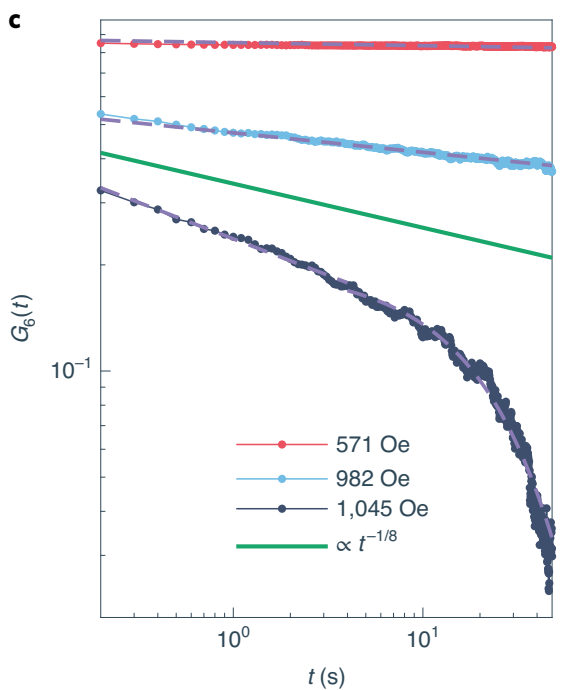

Fig. 3c | Original and corrected.

Published online: 8 September 2020

https://doi.org/10.1038/s41565-020-00774-3

(c) The Author(s), under exclusive licence to Springer Nature Limited 2020 